\title{
The Influence of Applied Force on Aluminium Foams Energy Absorption
}

\author{
Krešimir GRILEC*, Ivana BUNJAN, Suzana JAKOVLJEVIĆ
}

\begin{abstract}
Aluminium foams are composite materials made of aluminium or, frequently, of aluminium alloys. They have cellular structure consisting of metal matrix and gas filled pores and are occasionally produced with extrusion technologies. One of the ways to produce foamed aluminium is to mix Al powder with a blowing agent. That way, the blowing agent releases gas at higher temperatures and at the end, with different technologies and methods, such as extrusion technology, mixture is compacted. Nine samples of aluminium foams were produced from the following precursor Alulight AlMgSi0,6 titanium hydride $\mathrm{TiH}_{2}$ (cylindrical shaped, dimension $ø 42 \times 79,5 \mathrm{~mm}$, relative density between 0,186 and 0,268 . Aluminum foam investigated in this work had closed cells where quasi-static uniaxial compression was used to determine how applied force influences aluminium foams energy absorption properties. For energy absorption it is important to determine the critical force that will activate the maximum amount of absorbed energy. The dependence of energy absorption capacity and energy absorption efficiency on the compressive force was investigated, and then the obtained results were compared for different samples. By increasing the force, the energy absorption capacity of higher density foams increases faster. The energy absorption efficiency at low forces does not depend on the density of the samples but with increase of force, higher density foams become more efficient.
\end{abstract}

Keywords: aluminium foams; compression monitoring; energy absorption capacity; energy absorption efficiency; quasi-static uniaxial compression

\section{INTRODUCTION}

Foams, as highly porous materials, are a relatively new group of materials of great interest in industry because of their mechanical and physical properties [1]. Foams are materials with pores deliberately integrated in their structure. Structures are usually classified into two groups: honeycomb and foam structures. Honeycomb structures have two-dimensional regular array of cells, and foams possess three-dimensional polyhedral cells [2].

Foams, especially metallic foams, are having their breakthrough as a new material with great applicability. They are light-weighted because of their low density, have excellent damping and sound-absorbing capacity, and have good fracture and shear strength. Aluminium foams present relevant interests due to their unique structure combined with great mechanical properties, energy absorbing capacity, and low cost [3].

Aluminum foams are composite materials usually made of aluminium alloys where their cellular structure consists of metal matrix and gas filled pores [4]. One of the greatest advantages of aluminium foams are increased recyclability and their ecological harmlessness combined with exceptional lightweightness, which eventually tops aluminium foams as great material for transport sector [3, 4].

Production of aluminium foams with desirable properties is still complex and unpredictable - it is important to possess combination of theoretical and practical knowledge. Material processing has great effect on these properties; depending on them material will be strongly anisotropic. The field of interest are nonhomogeneous deformation patterns, such as strain localization, where they can be explained with the deformation of heterogenous highly porous material [4].

Main difference between regular materials and metallic foams is that the latter ones have excellent energy absorption properties and conversion of impact energy into deformation energy [5]. Many cellular solids are excellent energy absorbers owing to their deformation at a nearly constant stress level over a wide range of strain. In the future, metal foams might outperform conventional foams, e.g. polymer foams, because of their much higher strains
[1]. The goal is to optimize and make aluminium foams even better impact energy absorbers. Because of that, aluminium foam fillers are in the recent focus of researches. [3].

Metallic foams, especially aluminium ones, are used as energy absorbers e.g. buffer of automobiles, trains and trams. Automotive sector is continuously interested in these foams with a goal to reduce weight of the vehicles, while improving energy absorption capacity [1, 3]. The automotive industry has a massive use of aluminium foams in many major components, but foams have a complex natural geometry and their mechanical behaviour is still under investigation [6]. It should also be considered that in two foams with the same density, there is a possibility of different energy absorption. There is also no guarantee that two foams will have similar microstructure and shape of cells [7].

To achieve specific porous and cellular structure of aluminium foams, i.e. open- or closed-cell foams, various technologies and methods are used. Powder metallurgy technique consists of heating previously extruded mixture called precursor (aluminium alloy powder and foaming agent) to achieve cellular structure. Other methods are investing casting, sintering technique and addition of gas in melt injection. By changing the parameters of production, properties of porous are also being changed [8]. Many researches had been done experimentally about mechanical behaviour of aluminium foams, but there are some gaps that need to be filled by varying parameters and testing methods for energy absorption behaviour [9]. Way to improve energy absorption properties of aluminium foams is to have a higher relative density or the bonding between extrusion/foam. Studies about the effect of high nominal relative densities are not so abundant in the literature [3].

Because the investigation and experiments in this work were done only with the closed-cell foams, the following review of previous work are given briefly in the following. Usual way to determine compressive mechanical properties of produced aluminium foams is uniaxial tensile testing to investigate energy absorption capacity. The engineering stress engineering strain curves are then produced with information about plasticity of material, 
energy absorption capacity and where cracks appear [10]. Aluminium foams, as cellular metallic structure, show three different zones in their stress-strain compression curves. [11] Closed-cell aluminium foams have been thoroughly investigated and a large amount of previous works has focused on their global response [12]. Desphandeet. al [13] showed that compressive curves of closed-cell Alulight foam remained almost invariant within creased strain rate, but they all have same three definite regions, as mentioned in [11]. First region is the almost linear elastic region that is located between zero and compressive yield stress. Second region is constant plateau region consisted of area between compressive yield stress and densification strain. Third region is densification region, the region after densification strain [14]. When the first cell is broken in Alulight foam, due to the stress redistribution after the first fracture, other cells also begin to yield [15], which is correlated directly with different densities of aluminium foams [14].

Main goal of present and further investigations is to understand better aluminium foams energy absorption in correlation with different densities and different applied forces. Aluminium foams have complex structure that directly influences energy absorption capability. Addition to the investigation is the visualization of collapse of metallic foams where one can trace simultaneously crack propagation and collapse of foams, backed with numerical results.

\subsection{Production of Aluminium Foams}

To produce Alulight aluminium foam, as previously said, aluminium alloy powder is mixed with a product releasing gas. Mixture (precursor) is compacted and after that foaming procedure can begin. Mixture is heated at high temperatures where foaming agent can decompose and start releasing gas. Titanium hydride is widely used as a foaming agent and it starts decomposing at about $465{ }^{\circ} \mathrm{C}$, which is below the melting point of pure aluminium and its alloy $\left(660^{\circ} \mathrm{C}\right)[16]$.

Powder metallurgical route to aluminium foam starts with pure aluminium powder or aluminium alloy powder, which is combined with particles of, typically, titanium hydride. Those components are dry mixed. After that starts the process of pre-densification where the powder is cold compacted under cold isostatic pressing. Main goal is to succesfully extrude compacted powder into a bar or a plate of near theoretical density. That material is called 'precursor' and needs to be chopped to pre-forms for the next step of production. It is then placed inside split mould and heated to a little above the solidus temperature of the alloy. $\mathrm{TiH}_{2}$ decomposes at high temperatures and creates voids in aluminium alloy matrix with a high internal pressure. Voids expand by semi-solid flow and the result is swelling of aluminium, which creates the foam that fills the mould $[5,16]$.

After the foaming procedure, the mould is taken out of the furnace and cooled off. Cooling is the step in producing aluminium foam where the foam part of structure is frozen in shape and closed-cell aluminium foam is achieved. Aluminium foam also has thin casting skin on the surface. [17].

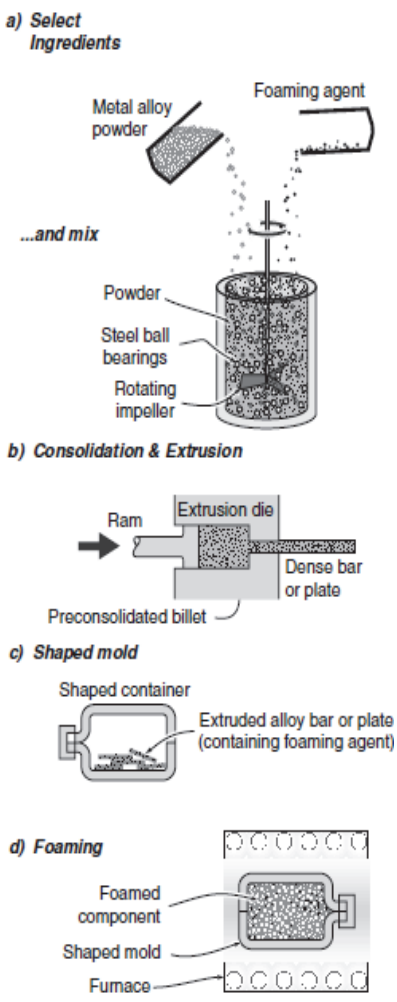

Figure 1 The part of powder metallurgical route to aluminium foams by gasreleasing particles in semi-solids [16]
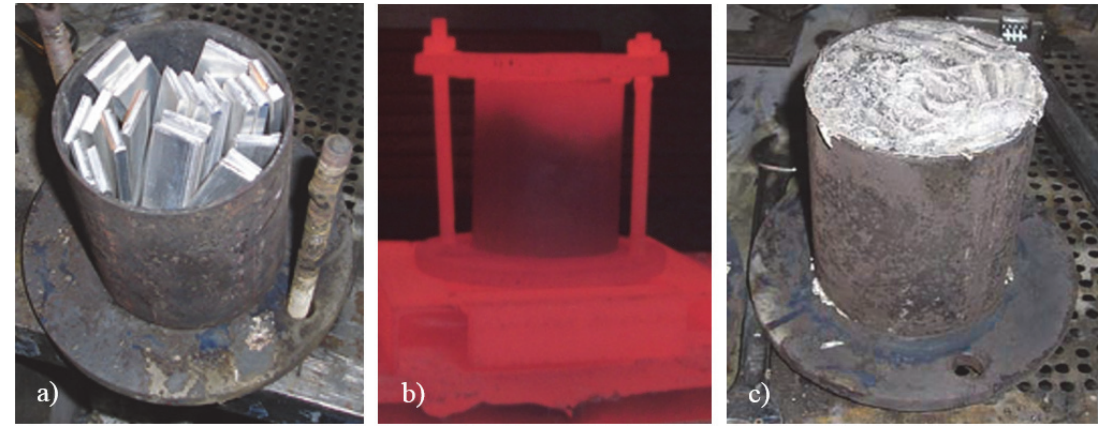

Figure 2 The final stage of production of aluminium foam: a) precursors placed inside a mould, b) mould during heating, c) sample inside a mould

Fig. 1 shows a complete process of metal foam production by gas-releasing particles in semi-solids. The final stage of metal foam production is shown in Fig. 2.

\subsection{Energy Absorption}

The energy absorption characteristics of materials play a major role in determining the crashworthiness of automotive structure [18]. The energy absorption capacity 
is defined as the energy necessary to deform a given specimen to a specific strain. By integrating the area under the stress-strain curve the absorption energy per unit volume for a sample, up to a strain, can be evaluated, namely [17]:

$$
W_{v}=\int_{0}^{\varepsilon_{0}} \sigma(\varepsilon) \mathrm{d} \varepsilon
$$

$W_{v}-$ absorbed energy per unit volume, $\mathrm{J} / \mathrm{mm}^{3}$

$\sigma-$ stress, $\mathrm{N} / \mathrm{mm}^{2}$

$\varepsilon-$ strain, $\%$

It is desirable for good energy absorbers to have a long flat stress-strain curve, as seen in Fig. 3

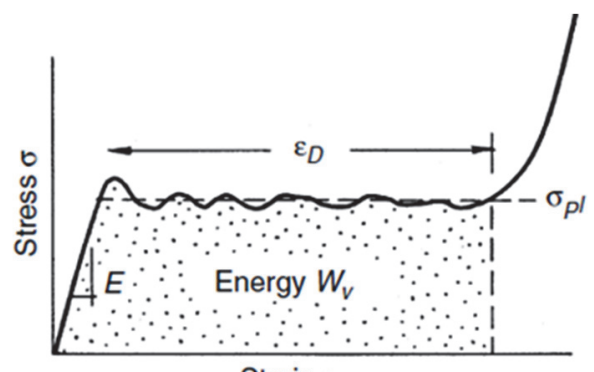

Strain $\varepsilon$

Figure 3 Stress-strain curve for an energy absorber ( $\sigma_{p l}$ - plateau stress, $\varepsilon_{D}-$ nominal strain) [16]

The energy absorption efficiency is the ratio of the actual absorbed energy and absorbed energy of the 'ideal' absorber. It compares the deformation energy absorbed by an investigated material or component with that of an 'ideal' energy absorber. An 'ideal' absorber reaches directly the maximum admissible strain of the load-compression curve, while it continuously keeps constant strain during the deformation process [19]:

$\eta=\frac{\int_{0}^{s} F\left(s^{\prime}\right) \mathrm{d} s^{\prime}}{F_{\max }(s) s}$

where $F_{\max }(s)$ is the highest force occurring up to the deformation $s$.

Energy absorption of tubes (or cylinders) depends on various interactions between different deformation modes such as bending and stretching, strain hardening effects, strain rate effects etc. The strain rate effects on energy absorption depend on the type of material, i.e. aluminium foam. The strain hardening effect of the material under impact increases the impact force and reduces the deformation [18].

\subsection{Samples of Aluminium Foam}

An electric furnace with a power of 7,5 $\mathrm{kW}$ was used for producing nine aluminium foam samples. Samples were shaped in cylindrical form (dimension $\Phi 42 \times 79,5$ $\mathrm{mm}$ ). Material used for production was Alulight AlMgSi0,6 $\mathrm{TiH}_{2}-0,4$ precursor. Tab. 1 shows mass, density and relative density of the samples.
Table 1 Samples of aluminium foam

Table 1 Samples of aluminium foam
\begin{tabular}{|c|c|c|c|}
\hline Sample & $\begin{array}{l}\text { Mass } \\
m / \mathrm{g}\end{array}$ & $\begin{array}{c}\text { Density } \\
\rho / \mathrm{kg} / \mathrm{m}^{3}\end{array}$ & $\begin{array}{c}\text { Relative density } \\
\rho_{r}\end{array}$ \\
\hline $4-1$ & 55,46 & 504,2 & 0,186 \\
\hline $4-2$ & 57,75 & 525,0 & 0,194 \\
\hline $4-3$ & 59,30 & 539,1 & 0,200 \\
\hline $4,5-1$ & 64,41 & 585,5 & 0,217 \\
\hline $4,5-2$ & 66,71 & 606,5 & 0,225 \\
\hline $4,5-3$ & 67,25 & 611,4 & 0,226 \\
\hline $5-1$ & 69,63 & 633,0 & 0,234 \\
\hline $5-2$ & 73,55 & 668,6 & 0,248 \\
\hline $5-3$ & 79,69 & 724,5 & 0,268 \\
\hline
\end{tabular}

\subsection{Quasi-Static Uniaxial Compression}

In this work, quasi-static uniaxial compression was carried out at WPM universal test machine, model EU40. The feed rate was $60 \mathrm{~mm} / \mathrm{min}$.

Addition to the experimental work was digital camera. It was used to record compression and samples after different forces. Results are shown in Fig. 4 to Fig. 7, but only for the lowest and highest foam density.

During compression at force $F=20 \mathrm{kN}$, Fig. 4, the foam with relative density $\rho_{r}=0,186$ showed significant portion of plastic deformation of cells. Strain reached value of $\varepsilon=0,364 \%$. The energy absorption efficiency was $\eta=$ 0,79 where $455,2 \mathrm{~J}$ of energy was absorbed. The foam with relative density $\rho_{r}=0,286$ compressed at force $F=20 \mathrm{kN}$ had only just entered the zone of plastic deformation where strain reached value of $\varepsilon=0,05 \%$. The amount of absorbed energy was almost 10 times smaller than that of the foam with relative density $\rho_{r}=0,186$. The energy absorption efficiency was also smaller, and it was $\eta=0,63$.

With increase of compression forces, Fig. 5 to Fig. 7, foams with relative density $\rho_{r}=0,186$ showed that energy absorption capacity was increasing, but the energy absorption efficiency was simultaneously decreasing. Compression at force $F=30 \mathrm{kN}$ already showed the limit of cell's collapsing - at that phase foams were basically compact material, and almost without cells.

During compression at force $F=40 \mathrm{kN}$, Fig. 6, the foam with relative density $\rho_{r}=0,268$ has only just begun showing significant plastic deformation where strain reached value of of $\varepsilon=0,27 \%$. It was still significantly smaller than that of the foam with relative density $\rho_{r}=$ 0,186 . Energy absorption efficiency was increasing to the force of $F=30 \mathrm{kN}$, and after further increasing of force, energy absorption efficiency was stagnated. The reason for that behaviour was that plateau regime of higher density foam was not that well defined as the one of the foam with relative density $\rho_{r}=0,186$. During compression at force $F$ $=50 \mathrm{kN}$, Fig. 7, the limit of cell's collapsing after force rapidly grew had still not been reached for the foam with relative density $\rho_{r}=0,268$. That was the reason why energy absorption efficiency and energy absorption capacity were still smaller than the ones of the foam with relative density $\rho_{r}=0,186$.

\section{RESULTS AND DISCUSSION}

The 'force-length reduction' curves (Fig. 8) were obtained as uniaxial compression test results. Low density foams have long flat force-length reduction curves. The force-length reduction curves are generally not overlapping but are similar in shape. In general, it can be 
concluded that the longer the plateau regime is, the lower the foam densities are. Of course, lower densities imply lower applied compressions.

Energy absorption capacity and energy absorption efficiency at different forces are calculated from these values and shown in Fig. 9 and Fig. 10.

Fig. 9 shows that the foams with lower densities absorbed more energy under smaller compression at forces
$F=20 \mathrm{kN}$ and $30 \mathrm{kN}$ than the foams with higher densities. Compression at force $F=40 \mathrm{kN}$ shows bigger energy absorption for foams with lower and middle densities than for foams with higher densities. But, when the highest compression at force $F=50 \mathrm{kN}$ was applied to samples, foams with middle densities showed the highest energy absorption. Lower density foams can absorb much more energy with greater length reduction.

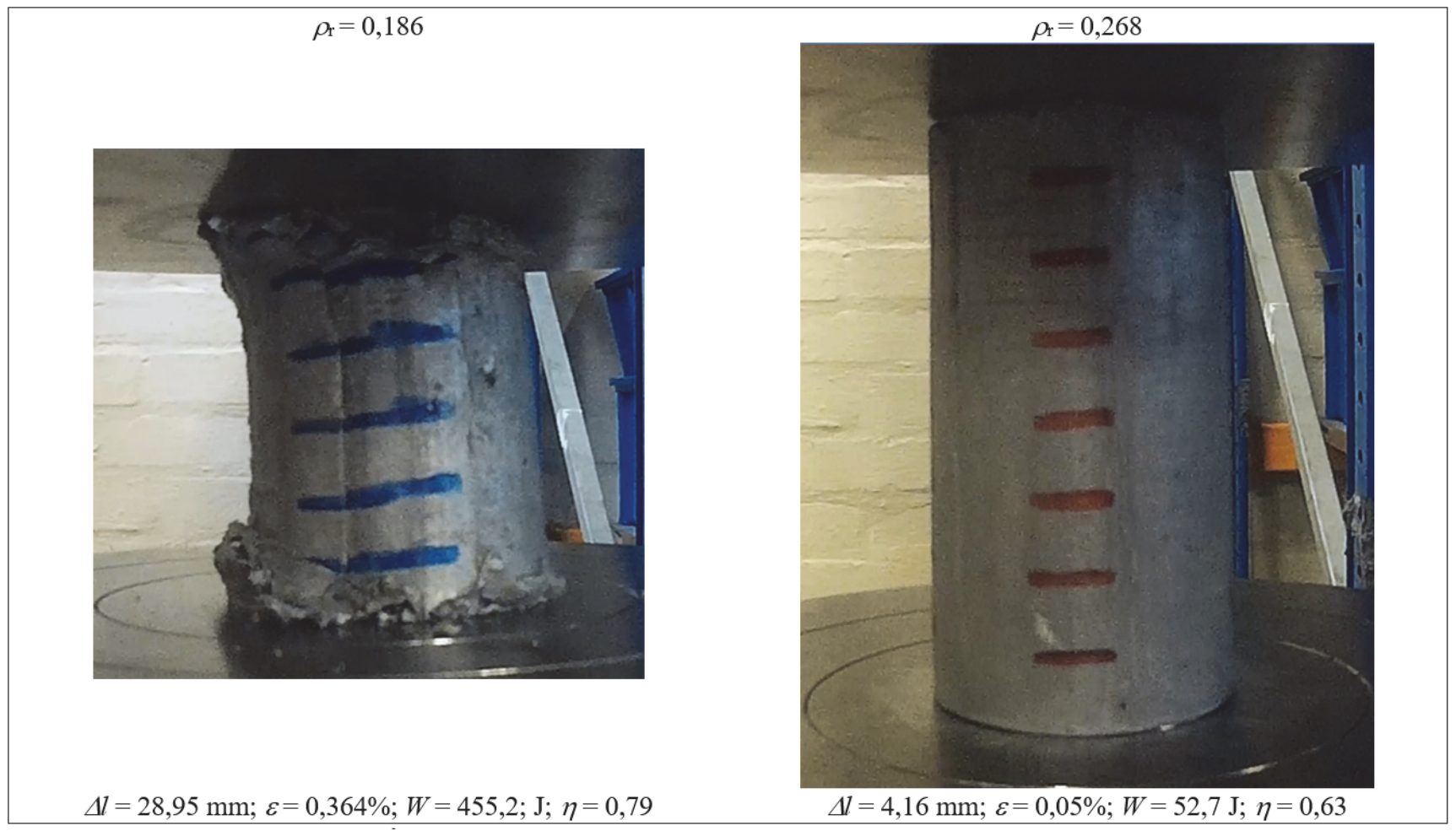

Figure 4 Compression at force $F=20 \mathrm{kN}$ (engineering stress $\sigma=14,436 \mathrm{MPa}$ )

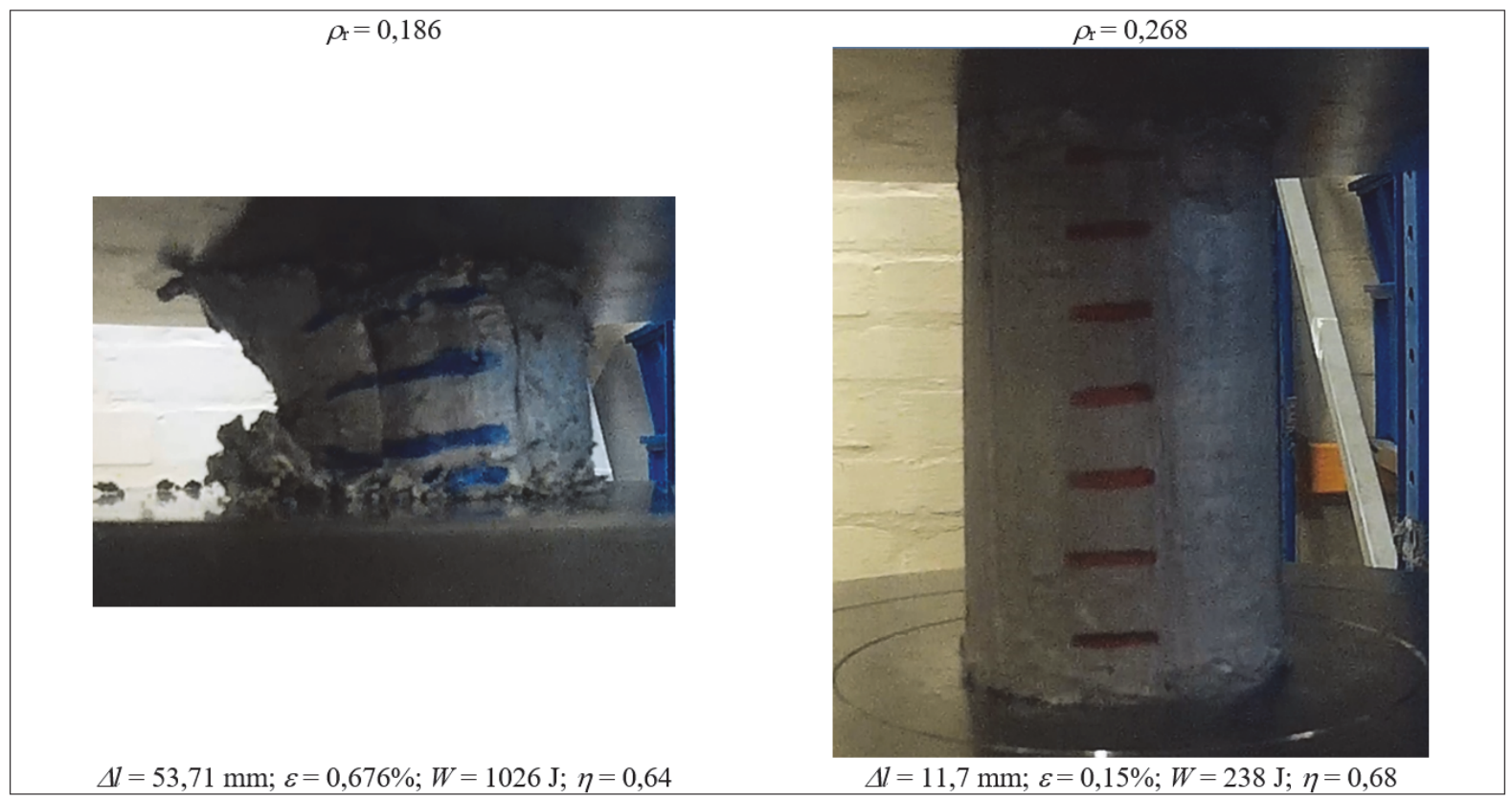

Figure 5 Compression at force $F=30 \mathrm{kN}$ (engineering stress $\sigma=21,654 \mathrm{MPa}$ ) 


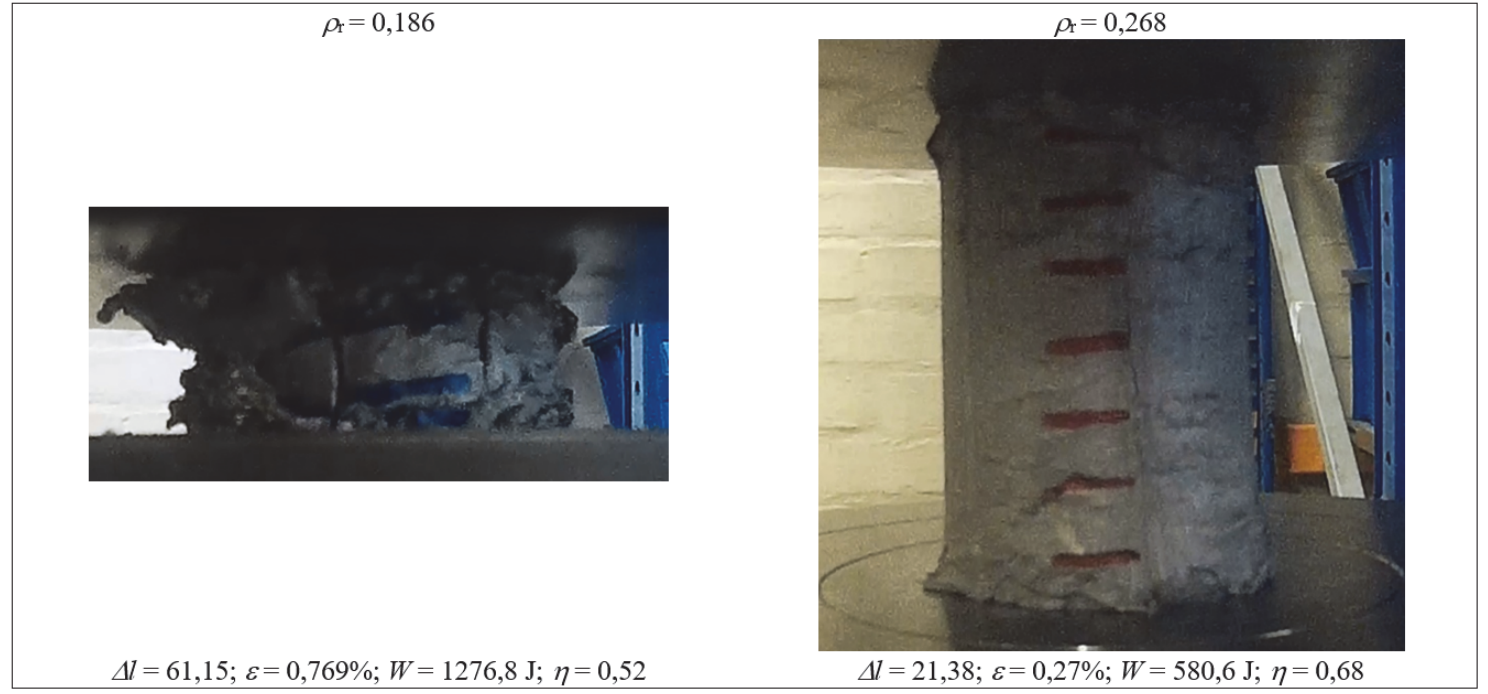

Figure 6 Compression at force $F=40 \mathrm{kN}$ (engineering stress $\sigma=28,872 \mathrm{MPa}$ )

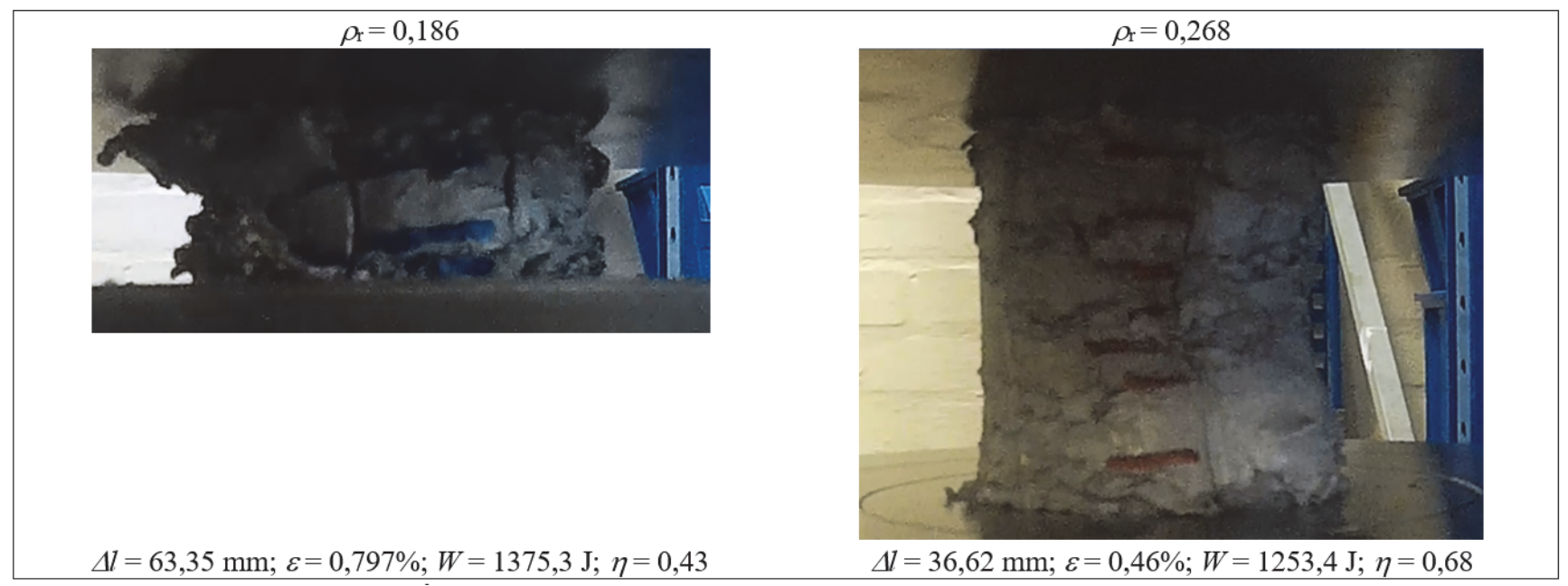

Figure 7 Compression at force $F=50 \mathrm{kN}$ (engineering stress $\sigma=36,090 \mathrm{MPa}$ )

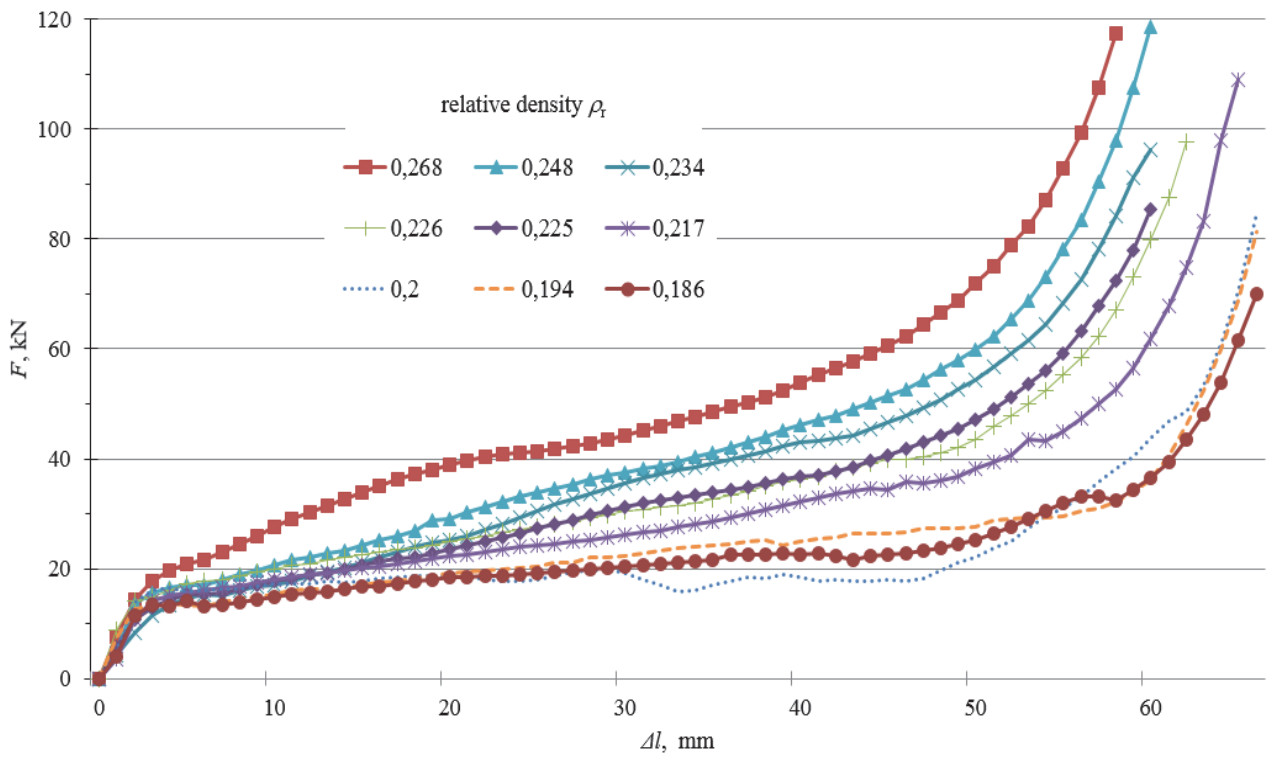

Figure 8 Force-length reduction curves for the tested samples

Fig. 10 shows that lower density foams had the greatest energy absorption efficiency under compression at force $F$ $=20 \mathrm{kN}$. In general, lower density foams showed the best energy absorption efficiency at almost every applied force. Foam with relative density $\rho_{r}=0.268$ was almost equally efficient at any applied force. 


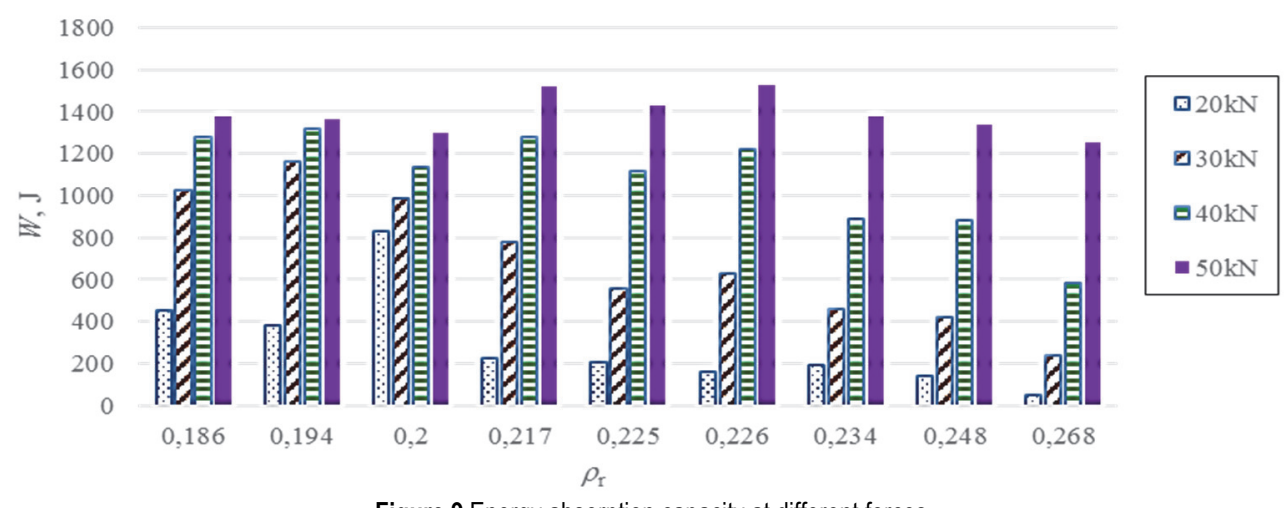

Figure 9 Energy absorption capacity at different forces

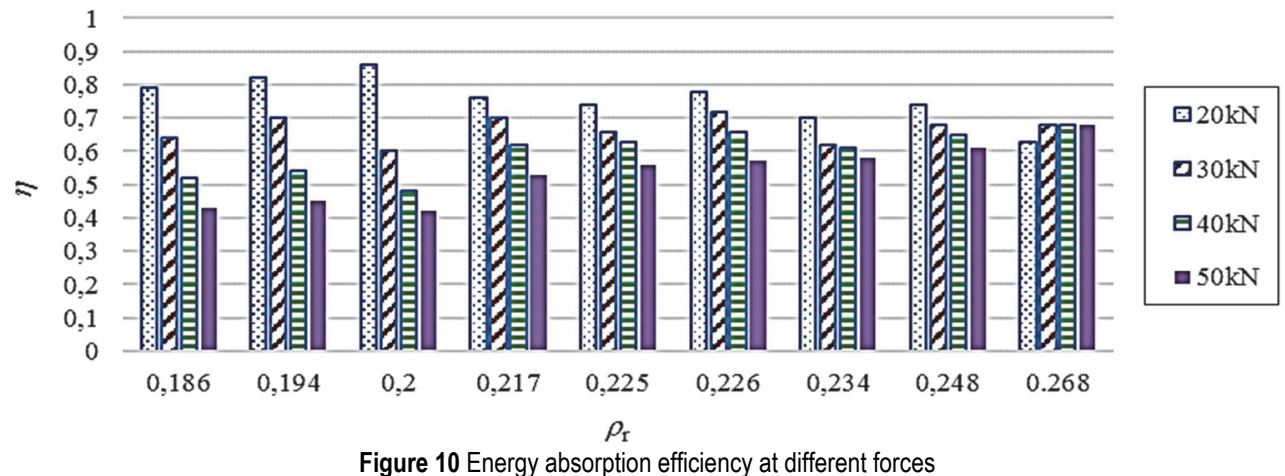

\section{CONCLUSION}

This paper presents experimental results of the influence of applied force on aluminium foams energy absorption. Closed-cell Alulight aluminium foams with different relative densities were investigated through quasi-static uniaxial compression. Obtained results showed that aluminium foams have good energy absorption capacity and efficiency. Energy absorption capacity at small forces increases with decreasing of aluminium foam density. If the force is increased, the energy absorption capacity of higher density foams increases faster. Lower density foams are more efficient at low forces, while higher density foams are more efficient with increase of force. The energy absorption capacity depends on the force. If that force is bigger than the force of plateau regime, the energy absorption capacity is going to be bigger. If plateau regime is not completely activated upon that force, the energy absorption capacity will be smaller. At large forces every sample has completely activated plateau regime. If it is completely activated, the energy absorption capacity of higher density foams is bigger.

With addition of a digital camera actual compression was captured. It gave opportunity to visually track length reduction based on the marks on the samples. This method is suitable for investigation of aluminium foams and it showed how the given results follow visual representation of samples.

\section{REFERENCES}

[1] Banhart, J. (2001). Manufacture, characterisation and application of cellular metals and metal foams. Progress in Materials Science, 46(6), 559-632. https://doi.org/10.1016/S0079-6425(00)00002-5

[2] Vemoori, R., Gurram, U., \& Khanra, A. K. (2019). Fabrication and Properties Evaluation of Alumina-Based
Open-Cell Foams. Transactions of the Indian Institute of Metals, 72(6), 1679-1682. https://doi.org/10.1007/s12666-019-01578-3

[3] Amaro, A. M., Neto, M. A., Cirne, J. S., \& Reis, P. N. B. (2019). Mechanical Characterization of Different Aluminium Foams at High Strain Rates. Materials, 12(9). https://doi.org/10.3390/ma12091428

[4] Badiche, X., Forest, S., Guibert, T., Bienvenu, Y., Bartout, J. D., Ienny, P., Croset, M., \& Bernet, H. (2000). Mechanical properties and non-homogeneous deformation of open-cell nickel foams: Application of the mechanics of cellular solids and of porous materials. Materials Science and Engineering: A, 289(1/2), 276-288. https://doi.org/10.1016(S0921-5093(00)00898-4

[5] Zhang, C., Feng, Y., \& Zhang, X. (2010). Mechanical properties and energy absorption properties of aluminium foam-filled square tubes. Transactions of Nonferrous Metal Society of China, 20(8), 1980-1386. https://doi.org/10.1016/S1003-6326(09)60308-3

[6] Sharma, V., Grujovic, N., Zivic, F., \& Slavkovic, V. (2019). Influence of Porosity on the Mechanical Behavior during Uniaxial Compressive Testing on Voronoi-Based Open-Cell Aluminium Foam. Materials, 12(7) 1041. https://doi.org/10.3390/ma12071040

[7] Talebi, S., Sadighi, M., \& Aghdam, M. M. (2018). Numerical and experimental analysis of the closed-cell aluminium foam under low velocity impact using computerized tomography technique. Acta Mechanica Sinica. https://doi.org/10.1007/s10409-018-0795-7

[8] Mahadev, M., Sreenivasa, C. G., \& Shivakumar, K. M. (2018). A Review on Production of Aluminium Metal Foams. IOP Conference Series: Materials Science and Engineering, 376, 012081. https://doi.org/10.1088/1757-899x/376/1/012081

[9] Endut, N. A., Al Hazza, M. H. F., Sidek, A. A., Adesta, E. T. Y., \& Ibrahim, N. A. (2018). Compressive Behaviour and Energy Absorption of Aluminium Foam Sandwich. IOP Conference Series: Materials Science and Engineering, 290. https://doi.org/10.1088/1757-899x/290/1/012084 
[10] Katona, B., Szlancsik, A., Tábi, T., \& Orbulov, I. N. (2018). Compressive characteristics and low frequency damping of aluminium matrix syntactic foams. Materials Science and Engineering: A, 739, 140-148. https://doi.org/10.1016/j.msea.2018.10.014

[11] Kader, M. A., Islam, M. A., Saadatfar, M., Hazell, P. J., Brown, A. D., Ahmed, S., Turner, M., \& Escobedo, J. P. (2017). Pore scale collapse mechanism of closed-cell aluminium foams during quasi-static compression. International Conference on Tomography of Materials and Structures, ICTMS2017-77. https://doi.org/10.1016/j.matdes.2017.01.011

[12] Saadatfar, M. et al. (2012). Structure and deformation correlation of closed-cell aluminium foam subject to uniaxial compression. Acta Materialia, 60(8), 3604-3615. https://doi.org/10.1016/j.actamat.2012.02.029

[13] Deshpande, V. S. \& Fleck, N. A. (2000). High strain Rate Compressive Behaviour of Aluminium Alloy Foams. International Journal of impact Engineering, 24, 277-298. https://doi.org/10.1016/S0734-743X(99)00153-0

[14] Linul, E., Marsavina, L., Kovacik, J., \& Sadowski, T. (2017). Dynamic and Quasi-Static Compression Tests of ClosedCell Aluminium Alloy Foams. Proceedings of the Romaniam Academy, Series A, 18(4), 361-369-

[15] Li, Q. M., Magkiriadis, I., \& Harrigan, J. J. (2006). Compressive Strain at the Onset of Densification of Cellular Solids. Journal of Cellular Plastics, 42(5), 371-392. https://doi.org/10.1177/0021955X06063519

[16] Ashby, M.F., Evans, A. G., Fleck, N. A., Gibson, L. J., Hutchinson, J. W., \& Wadley, H. N. G., (2000). Metal Foams: A Design Guide. Butterworth-Heinemann, BostonOxford-Auckland-Johannesburg-Melbourne-New Delhi

[17] Yi, F., Zhu, Z., Zu, F., Hu, S., \& Yi, P., (2001). Strain rate effects on the compressive property and the energyabsorbing capacity of aluminium alloy foams. Materials Characterization, 47(5), 417-422. https://doi.org/10.1016/S1044-5803(02)00194-8

[18] Simhachalam, B., Srinivas, K., \& Lakshmana Rao, C., (2014). Energy absorption characteristics of aluminium alloy AA7XXX and AA6061 tubes subjected to static and dynamic axial load. International Journal of Crashworthiness, 19(2), 139-152. https://doi.org/10.1080/13588265.2013.878974

[19] Baumeister, J., Banhart, J., \& Weber, M., (1997). Aluminium foams for transport industry. Materials \& Design, 18(4/6), 217-220.

https://doi.org/10.1016/S0261-3069(97)00050-2

\section{Contact information:}

Krešimir GRILEC, PhD, Professor

(Corresponding author)

University of Zagreb,

Faculty of Mechanical Engineering and Naval Architecture,

Ivana Lučića 5, 10000 Zagreb, Croatia

E-mail: kgrilec@fsb.hr

\section{Ivana BUNJAN, PhD student}

University of Zagreb,

Faculty of Mechanical Engineering and Naval Architecture,

Ivana Lučića 5, 10000 Zagreb, Croatia

E-mail: ivana.bunjan@fsb.hr

\section{Suzana JAKOVLJEVIĆ, PhD, Professor}

University of Zagreb,

Faculty of Mechanical Engineering and Naval Architecture,

Ivana Lučića 5, 10000 Zagreb, Croatia

E-mail: suzana.jakovljevic@fsb.hr 